\begin{tabular}{|c|c|c|}
\hline & \multirow{2}{*}{$\begin{array}{c}\text { International Journal of Current Research in } \\
\text { Biosciences and Plant Biology } \\
\text { Volume } 4 \text { • Number } 1 \text { (January-2017) • ISSN: 2349-8080 (Online) }\end{array}$} & $=$ \\
\hline & & \\
\hline $\begin{array}{l}\text { EXCELLEN } 1 \\
\text { PUBLISHERS }\end{array}$ & Journal homepage: www.ijcrbp.com & \\
\hline
\end{tabular}

\title{
Evaluation of Anti-fungal Activity of Coleus Species Extracts
}

\author{
Jacqueline Ebob Tarh* and Christian Ukwuoma Iroegbu
}

Department of Biological Sciences Cross River University of Technology, Calabar, Nigeria

*Corresponding author.

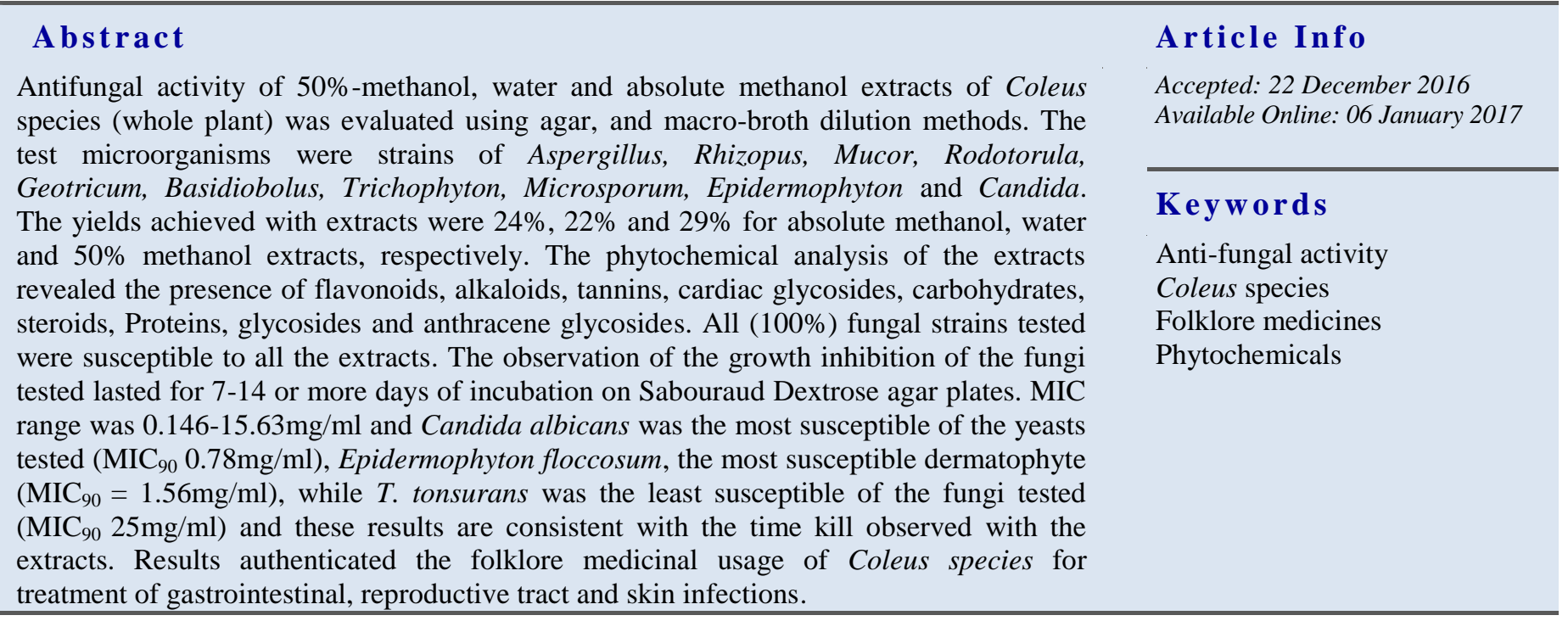

\section{Introduction}

Historically, man has always depended on plant sources for food, defense against enemies and for medicine. Every nationality and culture in the world has depended on herbal remedies, at one time or the other, for treatment of different diseases. The use of herbal remedies declined in favour of synthetic drugs particularly as the orthodox western medical practice gained ground worldwide. In recent times there has been resurgence of herbal treatment to the extent that herbal products (some distributed from the western countries), are seen everywhere neatly displayed on shelves, in markets and private clinics in Nigeria and other parts of the world. They have become a welcomed development given the rich plant diversities found in most countries where herbal remedies are patronized (Khare et al., 2011). Thus, these areas of the world are potential sources of indigenous natural products which could become important foreign exchange earners (Chirag et al., 2012) as well as help to reduce health care costs. Some of the issues in antimicrobial use of synthetic drugs include their inherent toxicity and frequent emergence of drug resistant strains of microorganisms. These factors have prompted the recent researches for therapeutic alternatives from plant sources (Ashok et al., 
2011; Chirag et al., 2012). The past two decades or so have witnessed renewed interest in medicinal plant research as source of new antimicrobial agents but many of the world's plant species have not been subjected to pharmacological and or biological tests for their biological activity and or antimicrobial activity (Senthilkumar et al., 2010).

In the Sub-Saharan African folk lore medicine, Coleus species and some members of this family Lamiaceae (Labiatae) have proven to have antiepileptic, antioxidant, anti-inflammatory, diuretic, nephroprotective activities, and anticlastogenic potency against anticancer drugs (Khare et al., 2011). They have been known to treat athlete's foot, skin, wound, gastrointestinal, respiratory, and urinary tract infections, bleeding, itching, fevers, asthma, allergies, sore throat, high blood pressure arthritis and infertility (Tarh et al., 2015). They have also been used as breast milk stimulant (Muhammad et al., 2013; Tarh et al., 2015). Coleus vettiveroides is used as a bitter cooling diuretic, trichogenous and antipyretic, also in hyperdipsia, vitiated conditions of pitta burning sensation, strangury, leprosy, leucoderma, vomiting, diarrhea and ulcers (Saraswathy and Lavanya, 2013). Coleus kilimanschari has been used to treat infections that destroy red blood cells (Mei et al., 2002). Murugesan et al. (2012) reported effect of Coleus forskohlii on intra-ocular pressure and hypotension, as well as it is anti-anaphylactic, amoebicidal, anti-platelet, gastroprotective, broncho-dilating, anti-cancer, anti- hair graying, antibacterial and antifungal activity. They also stated that it can be used as a research tool assessing the adenylate cyclase and cyclic AMP in cellular physiology, and as a condiment for heart ailments and stomach cramps .It was against this background that the work reported here set out to investigate the antifungal activity of Coleus species, with the aim of authenticating the folklore application of the plant in treatment of microbial infections.

\section{Materials and methods}

Coleus species, commonly known by the AnyangKendem people of Cameroon as Osem-antuoh, are edible aromatic perennial and mostly succulent herbs with square stems, toothed and opposite leaves, belonging to the mint family, Labiatae, and contains about 150 species (Tarh et al., 2015). Coleus blumei (Hybrid Coleus) has been reclassified under Solanostemon or Plectranthus genera and family Lamiaceae, a family of perennial plants native to tropical Africa, Asia, Australia, East Indies, Malay Archipelago and the Philippines (Ratnakaram et al., 2011). Variegated species of Coleus are very colourful, with scapploped or fringed, green, pink, maroon, bronze, yellow, red, crimson leaves, (sometimes confused with the unrelated Caladium). Example, Coleus fredericii has deep purple flowers in late winter or early spring, with thick brittle, fuzzy green leaves that have a strong aroma. Coleus species can grow up to 3-4 feet tall in moist drained soils. They do less well in subtropical areas than shaded areas, where their foliage colour tends to intensify, and are heat tolerant. They are typically grown as house hold plants and become leggy and unattractive with age (Ratnakaram et al., 2011). These famous plants belong to the peppermint and Basil family and have been known as kitchen, edible and aromatic perennial herbs

\section{Collection of plant materials}

Coleus species plants were collected from Kendem in the south west region of Cameroon as whole plants. The identification and authentication was done in the Department of Botany, University of Nigeria, Nsukka where voucher specimen was deposited. They were washed with distilled water, cut into tiny pieces and air dried in the dark. They were then ground to powder in a mortar, weighed and stored in plastic bags in the dark, dry place until they were used in the experiments that followed.

\section{Extraction of plant materials}

A $100 \mathrm{~g}$ weight of powdered plant material was soaked in $400 \mathrm{ml}$ of solvent (absolute methanol, water or $50 \%$ methanol in water) in a $1 \mathrm{~L}$ conical flask covered with cotton wool plugs. The flask was shaken vigorously at first and then intermittently for $24 \mathrm{hrs}$ leaving it in a water bath maintained at $40^{\circ} \mathrm{C}$ between the intervals of shaking. The mixture was filtered, first through three layers of clean muslin cloth, and then through Whatman no. 1 filter-paper. The filtrates were evaporated to dryness in a water bath at $56^{\circ} \mathrm{C}$ and the percentage yields of the crude extract determined (Tarh et al., 2015).

\section{Phytochemical analysis of plant extracts}

This analysis, which includes detecting the secondary metabolites present in the plant extracts, was carried out according to the methods described by Trease and Evans (1996). 


\section{Test organisms}

The fungi species used for the study were Trichophyton mentagropytes, Trichophyton tonsurans, Trichophyton violaceum, Microsporum gypseum, Microsporum canis, Epidermophyton floccosum, Candida albicans, Aspegillus species, Basidiobolus, Rodotorulla, Mucor, Rhizopus and Geotricum. They were cultured on Sabouraud Dextrose Agar plates at $25-35^{\circ} \mathrm{C}$ for $48 \mathrm{hrs}$ or more and the resultant pure mature colonies were subcultured on Sabouraud Dextrose Agar slants and stored as stock cultures.

\section{Standardization of fungal inocula}

The fungal inocula were prepared from the 7 to 14 days stock cultures grown on Sabouraud Dextrose Agar at 25$35^{\circ} \mathrm{C}$. Matured colonies were covered with $2 \mathrm{ml}$ of distilled water and suspensions were made by gently probing the colonies with a sterile loop or the tip of a Pasteur pipette. The resulting suspensions were transferred to sterile test tubes. Heavy particles were allowed to settle for about 3-5 minutes and the resultant supernatant homogenous mixtures or suspensions drained into sterile bottles. The colony forming units $(\mathrm{CFU})$ in the suspensions were counted using a haemocytometer and then the suspension diluted with Sabouraud dextrose broth to corresponds to the final standard inocula suspension (spores or yeast cells) of approximately $1 \times 10^{5}$ colony forming unit per $\mathrm{ml}$.

\section{Susceptibility testing of fungi by pour-plate method}

A $2.0 \mathrm{ml}$ amount of each reconstituted plant extract at the concentration of $1000 \mathrm{mg} / \mathrm{ml}$ was pipetted into two sterile glass test tube containing $18 \mathrm{ml}$ of molten Sabouraud Dextrose Agar (at about $45^{\circ} \mathrm{C}$ ). The mixtures were swirled carefully for the contents and agar to be thoroughly mixed. Then $100 \mu \mathrm{l}$ of the standard fungal inocula were seeded onto each of the tubes. Again they were thoroughly mixed and poured into each of the plates and allowed to set. They were then incubated at about $25-35^{\circ} \mathrm{C}$.

A sterile plate without the extract served as the positive control for growth while another plate containing $2.0 \mathrm{ml}$ of $16 \mu \mathrm{g} / \mathrm{ml}$ voriconazole as the negative control. As soon as growth was observed at the positive control plates the test plates were checked for growth daily and the period of inhibition of growth was recorded in days.
Determination of minimum inhibitory concentration (MIC) of the plant extracts on the fungi by Macrobroth dilution method

A two-fold serial dilution of the plant extract was carried out in tubes of Saboraud dextrose broth to obtain dilutions ranging from $200 \mathrm{mg} / \mathrm{ml}$ down to $0.39 \mathrm{mg} / \mathrm{ml}$. The $11^{\text {th }}$ tube, which was used as positive growth control culture, did not contain any extract. The control antimycotic agent, voriconazole, was similarly serially diluted but to attain concentrations ranging from 0.125 $128 \mu \mathrm{g} / \mathrm{ml}$. Each dilution was seeded with $100 \mu \mathrm{l}$ of the standardized suspensions of the test fungal spores and incubated at $25-35^{\circ} \mathrm{C}$ for $\geq 48 \mathrm{hrs}$. The lowest dilutions without visible growth in the tube cultures, compared to the positive and negative controls were considered as the MICs. The tests were carried out in quadruplets and the means of the MICs calculated.

Determination of minimum concentration at which $90 \%$ fungal growth inhibition was observed $\left(\mathrm{MIC}_{90}\right)$ from broth dilution tubes

A $100 \mu \mathrm{l}$ volume of the fungal test suspensions were taken from all the tubes showing no visible fungal growth and sub-cultured on Sabouraud Dextrose agar plates. These were incubated at $25-35^{\circ} \mathrm{C}$. Positive growth control plates were also included and checked simultaneously in comparison with the test plates for fungal growth. Any dilution showing 90\% growth inhibition was recorded as $\mathrm{MIC}_{90}$ (Sanguinetti et al., 2007). The Minimum Fungicidal Concentration (MFC) was considered as the minimum concentration of the test substances that yielded no visible growth on sub-culture of $100 \mu \mathrm{l}$ of serial dilutions and incubation at $35^{\circ} \mathrm{C}$ for more than $48 \mathrm{hrs}$.

Determination of the effects of plant extracts on viable colony forming units ( $\mathrm{CFU}$ ) of the fungi using Time-Kill (inhibition) assay

The effects of 50\% methanloic extracts of Coleus species were evaluated by a time-kill assay using the macrobroth dilution technique. The extracts were reconstituted in 20\% Dimethyl Sulfoxide (DMSO) and appropriately diluted to the required concentrations. The inoculums size was determined according to the type of fungus, (e.g. $1 \times 10^{6}$ for Candida albicans and $1 \times 10^{5}$ for dermatophytes). About $1.00 \mathrm{ml}$ of the extract was added to $9 \mathrm{ml}$ of Saboraud dextrose broth, seeded with the appropriate concentrations of the test fungus 
to achieve concentrations equivalent to $0.5 \times \mathrm{MIC}$, $1 \times$ MIC, $2 \times$ MIC, or $4 \times$ MICs values. Two sets of control tubes were included for each experiment. One set was seeded with the organism in broth without extract, and the other set contained broth without organism and extract. The control drug voriconazole was similarly diluted. All the fungal cultures were incubated at $25-35^{\circ} \mathrm{C}$ for $\geq 48 \mathrm{hrs}$. Immediately after inoculation of the tubes, aliquots of $100 \mu 1$ of the negative control tubes contents were taken, serially diluted in saline and seeded on nutrient agar plates to determine the zero hour counts. The same was done for the tubes which contained the test fungi after $0 \mathrm{hr}, 3$ hrs, $6 \mathrm{hrs}, 24 \mathrm{hrs}$ and $48 \mathrm{hrs}$, respectively. After incubation, the emergent colonies were counted and the mean count (CFU) of each test organism was determined and expressed as $\log _{10}$. The Minimum Lethal Concentrations (MLCs) of the extract were the lowest concentrations that gave $99.9 \%$ to $100 \%$ killing.

\section{Statistical analysis}

The data obtained was subjected to analysis of variance (ANOVA) using the Randomised Complete Block Design (Two-way analysis of variance) using SPSS version 13.0 (SPSS, 2003). Duncan's New Multiple Range Test was used to separate the means that were significantly different.

\section{Results}

Absolute methanol gave a yield of $24 \%, 22 \%$ for the water, while 50\%-methanol gave 39\%. Phytochemical analysis of Coleus species (whole plant) extracts showed the presence of alkaloids, flavonoids, tannins, cardiac glycosides, carbohydrates and steroids, glycosides, proteins and anthracene glycosides. No reducing sugars and saponins, were found in any of the plant extracts (Table 1).

Table 1. Phytochemical composition of whole plant extracts of Coleus species.

\begin{tabular}{llll}
\hline \multirow{2}{*}{ Phytochemicals } & \multicolumn{2}{l}{ Coleus species (whole plant)extracts } & $\mathbf{5 0 \%}$ methanol \\
\cline { 2 - 4 } & Absolute methanol & Water & ++ \\
\hline Alkaloids & + & + & +++ \\
Flavonoids & +++ & ++ & +++ \\
Tannins & ++ & ++ & - \\
Saponins & - & - & + \\
Cardiac glycosides & + & + & + \\
Glycosides & + & + & + \\
Proteins & + & + & + \\
Carbohydrates & + & + & - \\
Reducing sugars & - & - & ++ \\
Steroids & + & + & + \\
Antracene glycosides & + & + &
\end{tabular}

The 50\% methanolic extract of Coleus species inhibited the growth of the test fungi, namely, dermatophytes, Basidiobolus haptosporus, Rhodotorula species, Candida albicans, species of Aspergillus, Mucor, Rhizopus and Geotricum for $\geq 14$ days. The absolute methanolic extract as well as the aqueous extract inhibited the fungal growth for $\geq 12$ days (Table 2). The control antimycotic agent (voriconazole) inhibited the growth of all the fungal isolates tested for over 14days (Table 2).

The MICs and $\mathrm{MIC}_{90} \mathrm{~s}$ were evaluated using the $50 \%$ methanolic extract (the most potent or efficacious of the extracts) and Candida albicans emerged as the most susceptible fungus (MIC $0.146 \mathrm{mg} / \mathrm{ml}$ and $\mathrm{MIC}_{90}$ of
$0.78 \mathrm{mg} / \mathrm{ml})$. This was closely followed by B. haptosporus with $\mathrm{MIC}$ of $0.49 \mathrm{mg} / \mathrm{ml}$ and $\mathrm{MIC}_{90}$ of $1.56 \mathrm{mg} / \mathrm{ml}$. Among the dermatophytes tested, E. floccosum was the most susceptible with MIC $0.98 \mathrm{mg} / \mathrm{ml}$ and $\mathrm{MIC}_{90}, 1.56 \mathrm{mg} / \mathrm{ml}$ while $T$. tonsurans was the least susceptible with MIC of 15.63 and $\mathrm{MIC}_{90}$ of $25 \mathrm{mg} / \mathrm{ml}$ (Table 3 ).

For the control drug (voriconazole), C. albicans (MIC $0.313 \mu \mathrm{g} / \mathrm{ml}, \mathrm{MIC}_{90}$ of $0.5 \mu \mathrm{g} / \mathrm{ml}$ ), and T. rubrum (MIC $0.375 \mu \mathrm{g} / \mathrm{ml}, \mathrm{MIC}_{90}$ of $0.5 \mu \mathrm{g} / \mathrm{ml}$ ), were the most susceptible fungi while the least susceptible of the fungi was $B$. haptosporus at $\mathrm{MIC}$ of $1.25 \mu \mathrm{g} / \mathrm{ml}$, and $\mathrm{MIC}_{90}$ of $4 \mu \mathrm{g} / \mathrm{ml}$ (Table 3 ). 
Table 2. Fungal growth inhibition (in days) by Coleus species extracts.

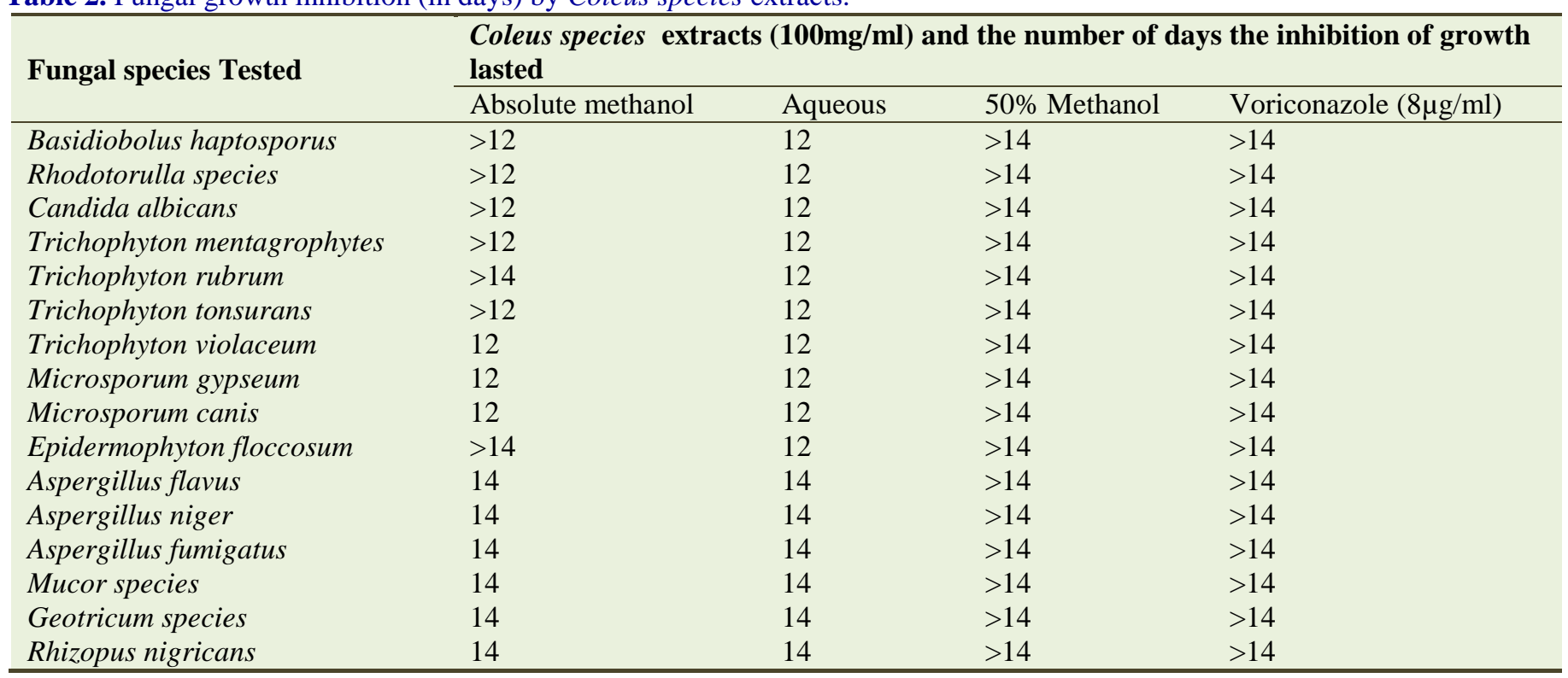

Table 3. Effects of $50 \%$ methanol extract of Coleus species on fungi.

\begin{tabular}{|c|c|c|c|c|}
\hline \multirow{2}{*}{ Fungi species } & \multicolumn{2}{|c|}{$\begin{array}{l}\text { Coleus species whole plant } \\
50 \% \text { methanol extract }(\mathrm{mg} / \mathrm{ml})\end{array}$} & \multicolumn{2}{|c|}{ Voriconazole $(\mu \mathrm{g} / \mathrm{ml})$} \\
\hline & $\begin{array}{l}\mathrm{MIC} \pm \mathrm{SD} \\
(\mathrm{mg} / \mathrm{ml})\end{array}$ & $\begin{array}{l}\mathrm{MIC}_{90} \\
(\mathrm{mg} / \mathrm{ml})\end{array}$ & $\begin{array}{l}\mathrm{MIC} \pm \mathrm{SD} \\
(\mu \mathrm{g} / \mathrm{ml})\end{array}$ & $\begin{array}{l}\mathrm{MIC}_{90} \\
(\mu \mathrm{g} / \mathrm{ml})\end{array}$ \\
\hline Candida albicans & $0.146 \pm 0.05$ & 0.78 & $0.313 \pm 0.13$ & 0.50 \\
\hline Rhodotorulla species & $0.39 \pm 0.00$ & 1.56 & $0.75 \pm 0.29$ & 2.00 \\
\hline Basidiobolus haptosporus & $0.49 \pm 0.195$ & 1.56 & $1.25 \pm 0.50$ & 4.00 \\
\hline Epidermophyton floccosum & $0.98 \pm 0.39$ & 1.56 & $0.313 \pm 0.13$ & 1.00 \\
\hline Trichophyton mentagrophytes & $1.37 \pm 0.59$ & 3.13 & $0.189 \pm 0.07$ & 1.00 \\
\hline Trichophyton rubrum & $1.95 \pm 0.78$ & 3.13 & $0.375 \pm 0.14$ & 0.50 \\
\hline Microsporum canis & $2.73 \pm 0.78$ & 3.13 & $0.25 \pm 0.00$ & 0.50 \\
\hline Trichophytonton surans & $15.63 \pm 6.30$ & 25 & $0.25 \pm 0.00$ & 1.00 \\
\hline Trichophyton violaceum & $1.37 \pm 0.39$ & 3.13 & $0.5 \pm 0.00$ & 1.00 \\
\hline Microsporum gypseum & $7.80 \pm 3.13$ & 12.50 & $0.75 \pm 0.29$ & 2.00 \\
\hline Aspergillus favus & $1.95 \pm 0.78$ & 1.56 & $0.25 \pm 0.00$ & 0.50 \\
\hline Aspergillus niger & $1.95 \pm 0.78$ & 1.56 & $0.25 \pm 0.00$ & 1.00 \\
\hline Aspergillus fumigatus & $1.37 \pm 0.59$ & 1.56 & $0.25 \pm 0.00$ & 1.00 \\
\hline Rhyzopus nigrcans & $1.95 \pm 0.78$ & 1.56 & $0.189 \pm 0.07$ & 1.00 \\
\hline Mucor species & $0.98 \pm 0.39$ & 3.13 & $0.375 \pm 0.14$ & 1.00 \\
\hline Geotricum species & $0.49 \pm 0.195$ & 3.13 & $0.75 \pm 0.29$ & 2.00 \\
\hline
\end{tabular}

\section{Time-Kill (inhibition) assay}

The exposure of $C$. albicans to varied concentrations of $50 \%$-methanol extract of coleus species, showed that 4MIC concentration $(1.17 \mathrm{mg} / \mathrm{ml})$ and Voriconazole $(0.5 \mu \mathrm{g} / \mathrm{ml})$ cleared Candida albicans viable cells in 24 hrs and 48 hrs, respectively (Fig. 1). Fungicidal activity was also observed even with the sub-inhibitory concentrations, i.e. $0.5 \mathrm{MIC}(0.14 \mathrm{mg} / \mathrm{ml})$.

Trichophyton mentagrophytes was killed in $3 \mathrm{hrs}$ by the
$4 \mathrm{MIC}(5.48 \mathrm{mg} / \mathrm{ml})$ concentration of $50 \%$-methanol extract of Coleus species, and in $48 \mathrm{hrs}$ by the control drug (voriconazole $1 \mu \mathrm{g} / \mathrm{ml}$ ) (Fig.2).

M. gypseum viable cells were totally undetectable after exposure to $4 \mathrm{MIC}$ and $2 \mathrm{MIC}(31.25 \mathrm{mg} / \mathrm{ml}$ and $15.6 \mathrm{mg} / \mathrm{ml}$ ) concentrations of $50 \%$ methanol extract of Coleus species in 3 hours and by the control drug at $2 \mu \mathrm{g} / \mathrm{ml}$ in $48 \mathrm{hrs}$ (Fig. 3). The fungicidal activity of the $50 \%$ methanol extract of Coleus species on E. floccosum was more prominent with the $4 \mathrm{MIC}$ and $2 \mathrm{MIC}$ 
$(3.9 \mathrm{mg} / \mathrm{ml}$ and $1.96 \mathrm{mg} / \mathrm{ml})$ concentrations (Fig. 4). These concentrations inhibited E. floccosum totally in



Fig. 1: Effect of $50 \%$ methanol extract of Coleus species (whole plant) on viable cell count of Candida albicans.

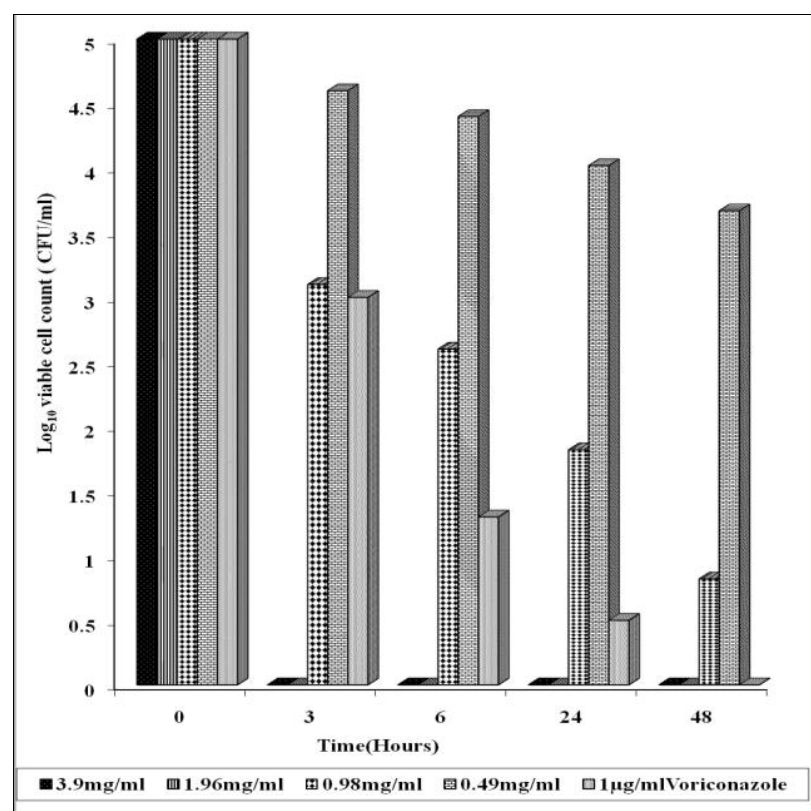

Fig. 3: Effect of $50 \%$ methanol extract of Coleus species (whole plant) on viable cell count of Microsporum gypseum.

\section{Discussion}

The comparatively high yield of extracts $(22 \%, 24 \%$ and $39 \%$ for water, Methanol and 50\% methanol, respectively) was consistent with the observation reported in Tarh et al. (2015) and compares favorably with the yields of $17.5 \%$ and $22.3 \%$ obtained by Majee et al. (2013) from respective water and methanol 3hours and $1 \mu \mathrm{g} / \mathrm{ml}$ of the control drug inhibited the fungal cells in 48hrs).

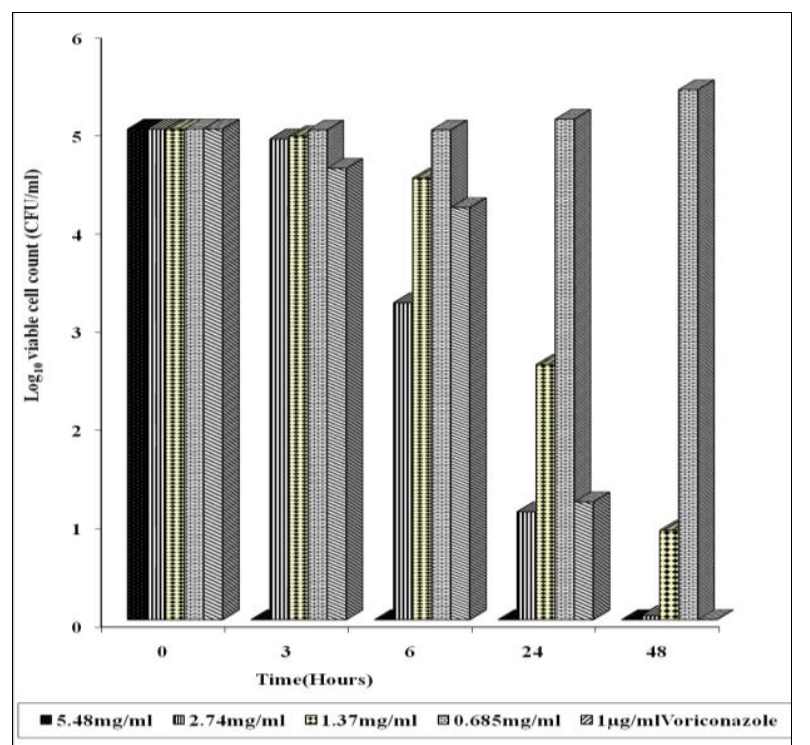

Fig. 2: Effect of 50\% methanol extract of Coleus species (whole plant) on viable cell count of Trichophyton mentagrophytes.

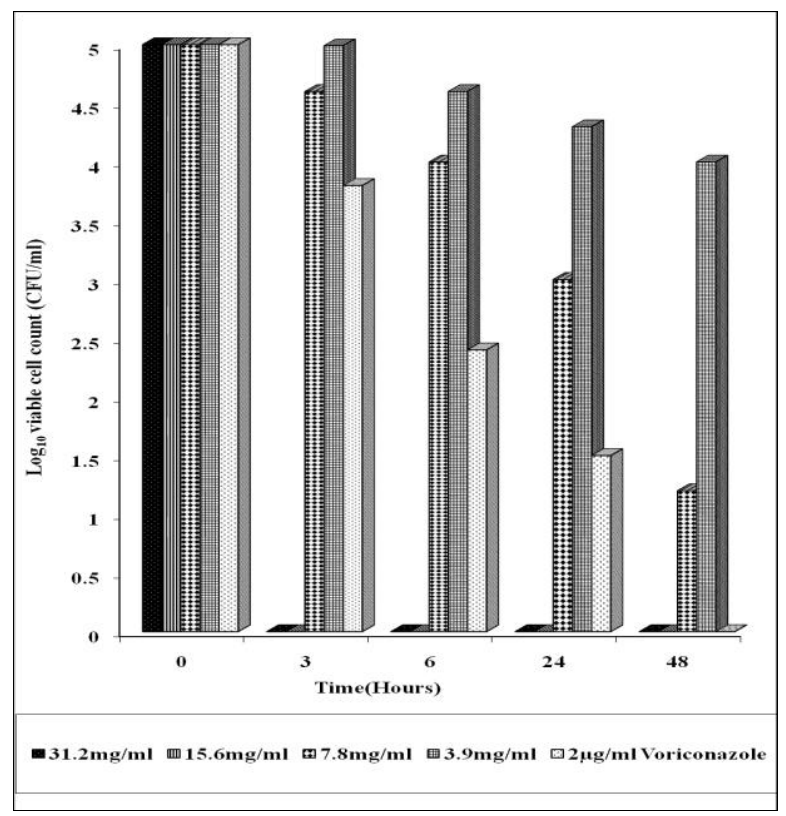

Fig. 4: Effect of 50\% methanol extract of Coleus species (whole plant) on viable cell count of Epidermophyton floccosum.

extracts of Coleus aromaticus leaves. The methanol extracts (50\% and absolute) inhibited growth of test fungal strains for longer period than the aqueous extract suggesting that they contained more efficacious and/or more stable bioactive compounds. Majee et al. (2013) observed a similar superior antimicrobial activity of hydro-alcohol extracts of Coleus aromaticus Bioactivity has also been reported for alcohol extracts of other 
Coleus species (Khare et al., 2011; Murugesan et al., 2012; Majee et al., 2013) against bacteria and or fungal strains. This is interesting given that in Kendem, southwest Cameroon where the plant materials were collected concoctions made by macerating parts of this plant in locally distilled gin is consumed for treatment of various ailments including microbial infections. Thus, the results of this work authenticate the use of this plant, particularly as alcohol preparation in ethno-medicinal practice in the region. The aqueous extract showed the least activity on all the test organisms which may imply that the water soluble constituents are not comparatively bioactive or the bioactivity may have been destroyed by hydrolysis.

In this study, the $\mathrm{MIC}_{90}$ values obtained, showed that the yeasts were significantly more susceptible (Candida albicans, $\mathrm{F}_{\mathrm{cal}}=0.896$, Rhodotorula, $\mathrm{F}_{\mathrm{cal}}=0.993$, $p=0.322)$ than the dermatophytes $\left(E\right.$. floccosum, $\mathrm{F}_{\mathrm{cal}}=$ $1.053 ;$ T. mentagrophytes, $\mathrm{F}_{\mathrm{cal}}=2.927$ and $M$. gypseum, $\mathrm{F}_{\text {cal }}=14.641$, respectively, $\left.p=0.001\right)$. Sub-inhibitory concentrations of some of the plant extracts killed Candida albicans. There was no significant difference between the values obtained by the macro broth dilution method and the agar dilution method $(p<0.05)$. This is unlike Guilhem et al. (2007) who reported that test methods influenced the results obtainable from susceptibility assays.

The rate at which the extracts killed the fungal cells varied with concentration of the extract, duration of exposure and test organism. The $100 \%$ killing of the viable cells recorded at different concentrations of the extracts and exposure intervals is very uncommon for crude plant extracts (Ibrahim et al., 1998). The fungicidal or fungistatic activity recorded at these concentrations for the extracts might have been dependent on the duration of exposure, and could be a combined effect of various constituents in the plant.

\section{Conflict of interest statement}

Authors declare that they have no conflict of interest.

\section{References}

Ashok, K., Sonia, S., Manoj, G., Ranveer, S., Ruchee, P., Priyanka, K.,2011. Antimicrobial activity of extracts of the medicinal plant Coleus forskohlii. Int. J. Drug Res. Technol. 1(1), 52-59.

Chirag, M., Shailesh, M., Hitesh, P., Ghanshyam, D.,
Avinash, K., Madhavi, A., 2012. Herbal antibacterials: A review. J. Intercult. Ethnopharmacol. 1(1), 52-61.

Guilherm, F.de.O., Nieg, A.J.C.F., Ademar, A.da.S.F., Carlos, H.G.M., Jairo, K. B., Wilson, R.C., Marcio, L.de A.eS., 2007. Antimicrobial activity of Syzygium cumini (Myrtaceae) leaves extracts. Braz. J. Microbiol. 38(2), 1-8.

Ibrahim, M.B., Owonubi, M.O., Onaolapu, J.A., 1998. Antimicrobial effects of leaf, stem and root bark of Anogiessus leicarpus on Staphylococcus aureus NCTC 8198, Escherichia coli NCTC 10418 and Protus vulgaris NCTC 4636. J. Pharmaceut. Res. Develop. 2, 20-26.

Khare, R. S., Banerjee, S., Kundu, K., 2011. Coleus aromaticus Benth. - A nutritive medicinal plant of potential therapeutic value. Int. J. Pharm. Biol. Sci. 2(3), B488-B500.

Majee, C., Das, G. K., Rupa, M., Chakraborthy, G. S., 2013. Evaluation of analgesic and antimicrobial potential of hydroalcoholic extract of leaves of Coleus aromaticus in albino mice. $\mathrm{J}$. Phytopharmacol. 2(3), 18-25.

Mei, S.X.B., Jiang, X.M., Niu, X.M., Li, M.L., Yang, H., Na, Z., Lin, Z. W., Li, C. M., Sun, H. D., 2002. Abietane diterpenoids from Coleus xanthanthus. J. Nat. Prod. 65, 633-637.

Muhammad, M. A., Khan, K., Muhammad, T., Abdulrahman, S., Bakar, I. A., Rizal, D., Azhary, Y., 2013. Anti-bacterial and anti-fungal activity of Coleus leaves consumed as breast-milk stimulant. Nutr. Food Sci. 43(6), 582-590.

Murugesan, S., Rajeshkannan, C., Sumathi, R., Manivachakam, P., Suresh, B.D., 2012. Bioactivity of root hexane extract of Coleus forskohlii Briq. Labiatae: GC/MS/MS characterization and identification. Eur. J. Exp. Biol. 2(5), 1469-1473.

Ratnakaram, S.T.K., Sathasivam, A., Elangovam, K., 2011. Evaluation of phytochemical and antibacterial activity of Plectranthus amboinicus. Int. J. Res. Ayur. Pharmacy. 2(1), 292-294.

Sanguinetti, M., Posteraro, B., Romano, L., Battanglia, F., Lopizzo, T., Decarolis, E., Fada, G., 2007. In vitro activity of Citrus bergamia (bergamot) oil against clinical isolates of dermatophytes. J. Antimicrob. Chemother. 59, 305-308.

Saraswathy, A., Mercy Lavanya, S., 2013. Chemical composition and antibacterial activity of the essential oil from the roots of Coleus vettiveroides K.C. Jacob. Int. J. Pharmacol. Biol. Sci. 3(3), 212217. 
Senthilkumar, C. S., Kumar, M. S., Pandian, M. R., 2010. In vitro antibacterial activity of crude leaf extracts from Tecoma stans (L.) Juss. Et Kunth, Coleus forskohlii and Pogostemon patchouli against human pathogenic bacteria. Int. J. Pharm. Technol. Res. 2(1), 438-442.

SPSS, 2003. Statistical Package for Social Sciences
Version 13.0, SPSS Inc.

Tarh, J. E., Okafor, J. I., Iroegbu, C. U., 2015. Evaluation of extracts of Coleus species for antibacterial activity. Afr. J. Biotechnol. 14(2), 125-132.

Trease, G. E., Evans, W.C., 1996. Pharmacognosy. $11^{\text {th }}$ Edn. Braillar Tiriden Company, MacMillan Publishers. pp.56-109.

\section{How to cite this article:}

Tarh, J. E., Iroegbu, C. U., 2017. Evaluation of anti-fungal activity of Coleus species extracts. Int. J. Curr. Res. Biosci. Plant Biol. 4(1), 131-138. doi: http://dx.doi.org/10.20546/ijcrbp.2017.401.017 